\title{
Research of the Issue of Lightening the Construction of the Gin Saw Cylinder
}

\author{
Juraeva Gulkhayo Ravshanbekovna, Muradov Rustam Muradovich, \\ Abduvakhidov Mutakhkhirkhon Mubashirovich
}

Namangan Engineering and Technological Institute, Namangan, Uzbekistan

Email: juraeva89@list.ru,rustam.m@list.ru,Mutahhir_74@mail.ru

How to cite this paper: Ravshanbekovna, J.G., Muradovich, M.R. and Mubashirovich, A.M. (2021) Research of the Issue of Lightening the Construction of the Gin Saw Cylinder. Engineering, 13, 224-235. https://doi.org/10.4236/eng.2021.134017

Received: March 11, 2021

Accepted: April 27, 2021

Published: April 30, 2021

Copyright () 2021 by author(s) and Scientific Research Publishing Inc. This work is licensed under the Creative Commons Attribution-NonCommercial International License (CC BY-NC 4.0). http://creativecommons.org/licenses/by-nc/4.0/

\begin{abstract}
The article investigates the problem of lightening the construction of the saw cylinder of the gin by drilling a central longitudinal through hole on the shaft and cutting circular holes on the saw blades. This is accompanied by a relatively large decrease in the mass of the saw cylinder and a relatively smaller decrease in the axial moment of inertia of the cross-sectional area of the shaft, which provides the maximum deflection of the saw cylinder under the action of its own gravity in the middle of the span is from $0.450 \mathrm{~mm}$ to $0.406 \mathrm{~mm}$.
\end{abstract}

\section{Keywords}

Gin, Movable Object, Saw Cylinder, Shaft, Saw Blade, Axial Moment of Inertia, Cross-Section, Deflection, Circular Hole

\section{Introduction}

In the machines of the cotton ginning industry, a significant number of composite movable objects are used with the use of force factors for design purposes.

These include the gin saw cylinder, the gin roll, the fiber cleaning machine saw cylinders, the first and second transition linter saw cylinders, the 4-COM type metal delinter drum and the ring delinter saw cylinder.

The design feature that unites the movable objects of this category into one group is the formation of a package of flat elements capable of working not only in compression, but also in bending and torsion with the help of a longitudinal compression force imparted by the shaft.

The magnitude of the compressive force directed along the geometric axis of the package is usually sufficient for the entire structure to work as a monolithic body. The most typical representatives of such batch working bodies of this group are saw cylinders of various designs, which have all the most important 
common design features.

As theoretical and practical studies show, the results obtained during their research and to a certain extent extend to other types of composite working bodies used in practice.

The saw cylinder is the main working body of the saw gin and consists of a shaft, saw blades and inter-groove spacers [1].

In Figure 1, a saw cylinder is shown, which includes a saw shaft 5, saw blades 3 , inter-groove spacers 2 , washers 1 , right and left clamping nuts 4 . One end of the saw shaft is closed with a safety sleeve, and the other is connected to the motor shaft through a semi-rigid coupling.

Due to the peculiarities of the performed technological functions, the most important mechanical parameters of the sawing tools are bending stiffness, as well as tensile-compression and torsional stiffness.

This is primarily due to the fact that not only the quality of cotton fiber, but also the technological reliability of machines with composite working bodies strongly depend on the size and stability of the gaps between saws and grates.

The size of the gaps depends on the size of the deflection of the working body, the tolerance for which is $0.3 \cdots 0.4 \times 10^{-3} \mathrm{~m}$ [1]. At the same time, it was revealed that the static deflection of the gin saw cylinder under the action of its own gravity and technological load at a normal value of the tightening force reaches $1.6 \times 10^{-3} \mathrm{~m}$, and the amplitude of the oscillations in the operating speed zone is $(0.5 \cdots 0.6) \times 10^{-3} \mathrm{~m}$, and in the zone of critical speeds $(1.5 \cdots 3.5) \times 10^{-3}$ $\mathrm{m}[1]$.

The problem is compounded by the fact that the operating speeds of the saw cylinders are directly adjacent to their first critical speeds. It should be noted here that the values of the critical speeds are determined mainly by the ratio of the parameters of stiffness and mass, as well as the moment of inertia of the mass of the saw cylinder. Moreover, these parameters are largely determined by the saw cylinder shaft. It should be noted that, taking into account the foregoing, important parameters are the relative bending compliance of the saw cylinder $\mathrm{h} p$ and the saw cylinder shaft $\mathrm{h} b$, which can be characterized by the ratios of the values of the maximum deflections of the saw cylinder $\mathrm{f} p$ and the saw cylinder shaft $\mathrm{f} b$, under the action of gravity in the middle of the span by the span length $1 p \mathrm{~mm} / \mathrm{m}$ and $1 \mathrm{w} \mathrm{mm} / \mathrm{m}$.

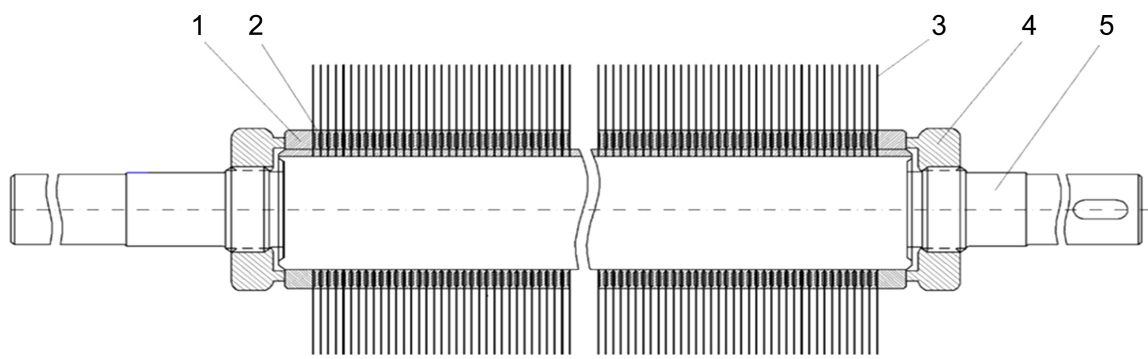

Figure 1. Sawing cylinder of 4DP-130 brand saw gin. 1-washer; 2-mezhduilny gasket; 3-saw blade; 4-nut; 5-shaft. 
In connection with the above, the issue of a significant distance between critical speeds and operating speeds by reducing the maximum deflection of the saw cylinder under the action of its own gravity in the middle of the span is extremely important. This current goal can be achieved by improving the design of the saw cylinder shaft and or the saw package and shims.

\section{Research on the Improvement of the Saw Cylinder Shaft Design}

To begin the study, let us consider the determination of the bending stiffness and relative bending compliance of the existing design of the saw cylinder shaft (Figure 2) and the saw cylinder of the 4DP-130 sawing gin (Figure 1).

The saw cylinder shaft of a $4 \mathrm{DP}-130$ saw gin (Figure 2) is represented a supported cylindrical body with the following main mechanical parameters:

- shaft diameter $D=100 \mathrm{~mm}$;

- the length of the working part of the shaft $1=2370 \mathrm{~mm}$;

- shaft material-steel 45;

- the density of the shaft material $\gamma=7.8 \times 10^{-3} \mathrm{~g} / \mathrm{mm}^{3}$;

- module of elasticity of the shaft material; $E=2.1 \times 10^{5} \mathrm{~N} / \mathrm{mm}^{2}$;

- axial moment of inertia of the shaft cross-section $J=\frac{\pi D^{4}}{64}=4.906 \times 10^{6} \mathrm{~mm}^{4}$;

- uniformly distributed load on the shaft from the gravity forces of the saw elements.

cylinder:

shaft within the working span; $Q_{\text {shaft }}=\pi R^{2} l \gamma=1590 \mathrm{~N}$.

saw; $Q_{\text {saw }}=689 \mathrm{~N}$.

gaskets; $Q_{\text {gas }}=314,4 \mathrm{~N}$.

two nuts; $Q_{n u t}=36 \mathrm{~N}$.

The total value of the gravity forces of the elements of the saw cylinder:

$$
Q_{\text {value }}=1590.0+689.0+314.4+36.0=2629.4 \mathrm{~N}
$$

Consider the case of loading a shaft with a uniformly distributed load from the shaft's own gravity $Q_{\text {shaft }}$. Then the value of the maximum shaft deflection $f_{b}$ under the influence of its own gravity in the middle of the span of the saw cylinder of the 4DP-130 saw gin:

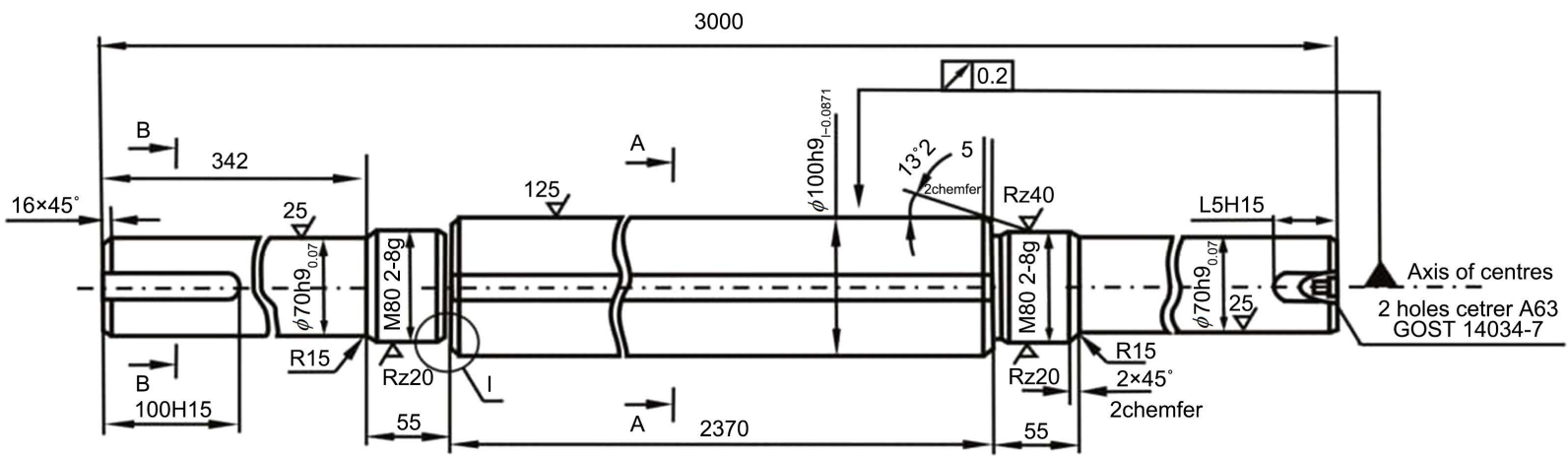

Figure 2. Shaft design. 


$$
f_{6}=\frac{5 Q_{\text {sal }} l^{3}}{384 E J}=0.27 \mathrm{~mm}
$$

Then the relative flexural compliance of the shaft will be equal to:

$$
h_{6}=\frac{f_{B}}{l}=\frac{0.27}{2.37}=0.114 \mathrm{~mm} / \mathrm{m}
$$

Now let us determine the value of the maximum deflection $f_{u}$ of the saw cylinder of the $4 \mathrm{DP}-130$ saw gin in the middle of the span $Q_{v a l}$ under the action of its own gravity. In this case, the shaft is loaded with a uniformly distributed load from the sum of the gravity forces of the shaft $Q_{\text {shaft }}$, saws $Q_{\text {saw }}$, gaskets $Q_{\text {gas }}$ and clamping nuts $Q_{n u t}$.

The value of the maximum deflection $f_{u}$ of the saw cylinder of the 4DP-130 saw gin under the influence of its own gravity in the middle of the span:

$$
f_{u}=\frac{5 Q_{c y s} l^{3}}{384 E J}=0.45 \mathrm{~mm}
$$

Then the relative bending compliance of the saw cylinder will be determined:

$$
h_{u}=\frac{f_{u}}{l}=\frac{0.45}{2.37}=0.190 \mathrm{~mm} / \mathrm{m}
$$

The problems of improving the design of the saw cylinder shaft and the package of saws and gaskets by reducing their relative bending flexibility can, in principle, be solved in several ways:

1) An increase in the value of the compression force of the saw pack and saw cylinder gaskets to increase the additional bending stiffness resulting from this.

2) By changing the bending stiffness, the operating speed of the saw cylinder, or both at the same time, so that the saw cylinder operates in flex shaft mode.

3) By significantly reducing the mass and moments of inertia of the elements of the saw cylinder without reducing their geometric parameters.

4) By significantly reducing the mass of the saw shaft with less a significant decrease in the moment of inertia of the area of the transverse section of the saw shaft.

5) By significantly reducing the weight of the saw package elements and saw cylinder shims with constant saw shaft parameters.

6) By various combinations of options of the listed methods.

Let's conduct a preliminary comparative analysis of the features of the listed methods for solving the problem.

The first method is based on the analytical dependence of the value of the additional bending stiffness of a package of flat elements-saws and gaskets on the value of the compressive force of the package $N$, established in [2]:

$$
C=2\left(l+\lambda_{c}\right)\left(N+\lambda_{q} E F\right) R^{2}
$$

where: $l$-thickness of flat elements;

$\lambda_{c}$ - the total function of the influence of the thickness of flat elements in the form of saw blades and spacers, and the forces of friction between them; 
$\lambda_{q}$-the function of the influence of additional longitudinal forces arising from the bending of the axis of the flexible shaft tightening the package;

$N$-is the value of the force of compression of the package;

$E$-modulus of elasticity of the material of the tightening thread or shaft;

$F$-is the cross-sectional area of the bundle of saw blades and shaft spacers;

$R$-is the radius of the contact area of flat elements in the form of working saw blades and spacers.

The first method makes it possible to increase the bending stiffness of the gin saw cylinder up to four times, and the critical frequency for bending vibrations up to two times. A feature of the method is the need to use special equipment for assembling the saw cylinder.

The second method requires the saw cylinder to work in the mode flexible shaft, which requires the fulfillment of the condition:

$$
\omega_{\text {work }} \geq 1.3 \omega_{\text {circ }}
$$

where: $\omega_{\text {work }}$-the operating frequency of the saw cylinder;

$\omega_{\text {circ }}$-is the critical frequency of the saw cylinder.

For the implementation of the method requires the preliminary implementation of a large complex of research work to determine the design and technological conditions, providing an increase in the operating speed of the saw cylinders by $1.5-2$ times [3].

In the third method, the materials of the elements of the saw cylinder are replaced with lighter ones without changing the structures of the elements, which ensures a decrease in the mass and moments of inertia of the elements' masses while maintaining the strength parameters to the maximum. The success of replacing the materials of the elements of the working body with lighter ones depends on the mechanical parameters, the price of the lighter material and its availability.

In the fourth method, changes are made to the shaft design, providing a significant reduction in the mass and moments of inertia of the shaft mass with a slight decrease in the moments of inertia of the cross-sectional area of the shaft.

In the fifth method, changes are made to the design of the saw pack and saw cylinder gaskets, which ensure a decrease in the mass and moments of inertia of the elements' masses while maintaining the maximum stiffness of the saw cylinder.

Finally, with the sixth method, the designs of both the shaft and the package of saws and gaskets are changed, which ensure the maximum reduction in the mass and moments of inertia of the elements of the saw cylinder while maintaining the stiffness parameters of the saw cylinder.

Thus, the simplest and most accessible methods are the fourth and fifth methods and their combination, which consists in making changes in the design of both the package of saws and gaskets, and the shaft, providing the maximum reduction in the mass or moments of inertia of the elements of the saw cylinder while significantly maintaining the values moments of inertia of the cross-sectional 
areas of the saw cylinder shafts.

Let's carry out a comparative analysis of the proposed solutions to the problem.

First, consider solutions for improving shaft designs. In [2], one of the proposed solutions to the problem of developing a lightweight construction of the saw cylinder of the genie is given, the general structure of which is illustrated by Figure 3 and Figure 4.

The essence of the developed design lies in the fact that the saw cylinder of the gin contains a shaft, saw blades mounted on it with tongues made symmetrically on both sides, entering the corresponding grooves of the shaft. On the surface of the shaft, there are splines, there are gaskets, washers and clamping nuts.

The longitudinal splines made on the surface of the shaft play the role of stiffeners and can significantly reduce the mass of the shaft, while maintaining to a large extent the flexural rigidity of the shaft, which ensures the production of cotton fiber with the required quality indicators.

The lightweight construction of the gin's saw cylinder is illustrated by the following drawings: in Figure 3, a general view of the gin's saw cylinder, in Figure 4 , the cross-section of the shaft and the saw blade with tongues.

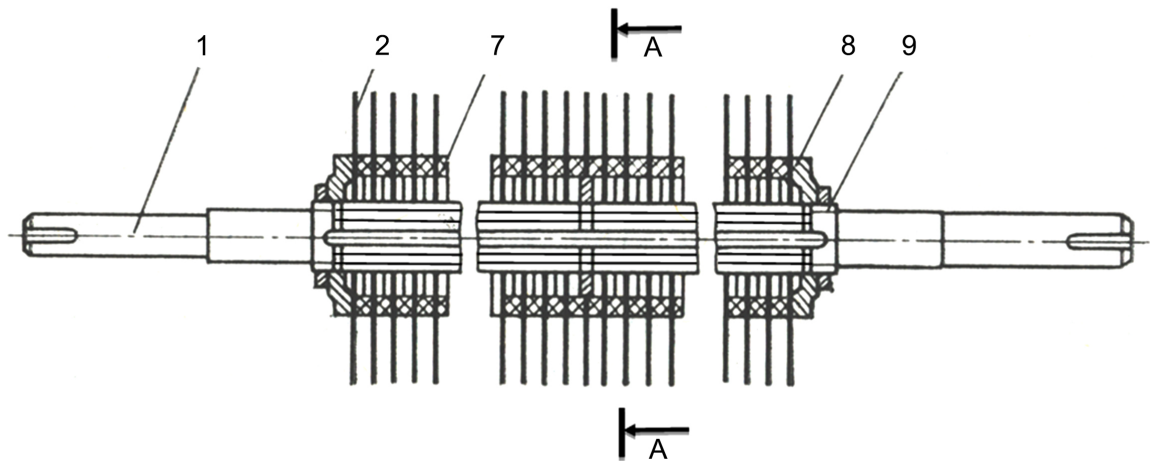

Figure 3. A variant of improving the design of the saw cylinder of the gin. 1 -splined shaft with longitudinal grooves, 2-saw blades with symmetrically made tongues, 7-groove pads, 8-washers, 9-clamping nuts.

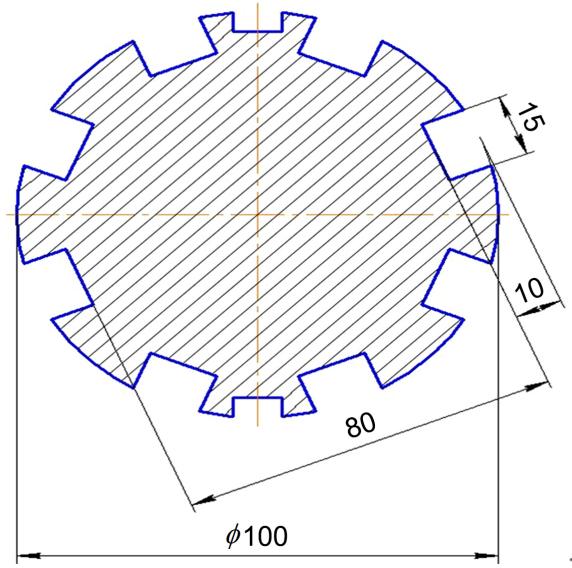

(a)

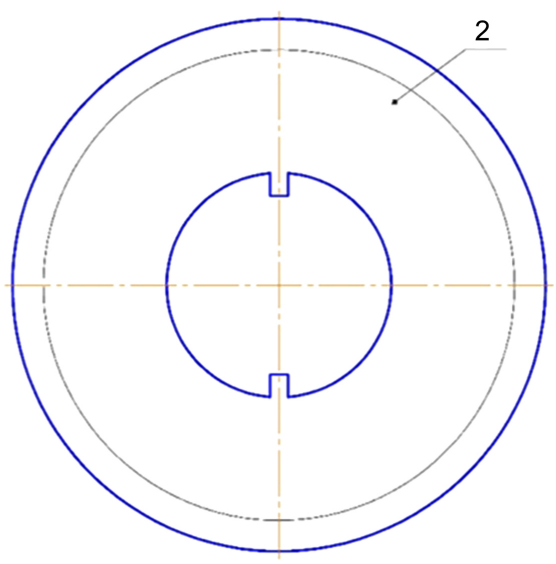

(b)

Figure 4. (a) cross-section of the shaft; (b) saw blade with tongues. 
The design works as follows. In the process of work, when feeding raw cotton, the saw blades grab strands of fibers and drag them by the grates (not shown in Figure 4). In this case, cotton seeds, the sizes of which exceed the technological gap between the grates, are delayed and a strand of fibers, carried away by the saws from the seeds, is detached.

It is argued that reducing the mass of the gin saw cylinder due to the design of the spline shaft, provides a deflection within acceptable limits, improves reliability, reduces the power consumption of the gin, and produces high quality cotton fiber at high productivity. Execution of saw blades with tongues on both sides symmetrically and corresponding grooves on the shaft during operation leads to the absence of imbalance and static balancing of the masses of the system relative to the axis of rotation.

The shaft is considered as a freely supported cylindrical body with the following changes in the main mechanical parameters:

1) Reduction of the gravity force of the shaft $Q$. Since the lengths of the grooves are unchanged and equal to the working length of the shaft, the relative decrease in the force of gravity is equal to the relative decrease in the cross-sectional area of the shaft.

The cross-sectional area of the shaft is equal to:

$$
S_{6}=\pi R^{2}=3.14 \times 2500=7850 \mathrm{~mm}^{2}
$$

The total cross-sectional area of the grooves will be equal to:

$$
S_{n}=6 \times 15 \times 10+2 \times 5 \times 10=1000 \mathrm{~mm}^{2}
$$

Then the absolute decrease in the shaft's gravity will be:

$$
Q_{y a}=\frac{S_{n}}{S_{E}}=\frac{1000}{7850} 159=202 \mathrm{~N}
$$

2) Reduction of the axial moment of inertia of the cross-section of the shaft due to spline grooves:

$$
8 \times 15 \times 10 \times 45^{2}=2.43 \times 10^{6} \mathrm{~mm}^{4}
$$

eduction of the axial moment of inertia of the cross-section of the shaft due to the grooves for the saw tongues:

$$
2 \times 5 \times 10 \times 47.5^{2}=2.26 \times 10^{5} \mathrm{~mm}^{4}
$$

General reduction in the axial moment of inertia of the shaft cross-section due to spline grooves and grooves for saw tongues:

$$
J_{y o}=2.43 \times 10^{6}+2.26 \times 10^{5}=2.61 \times 10^{6} \mathrm{~mm}^{4}
$$

An important parameter of the saw cylinder is the maximum deflection due $f_{d}$ to its own gravity in the middle of the span.

An important parameter of the saw cylinder shaft is the value of the maximum deflection $f_{d}$ under the action of its own gravity, taking into account the influence of the spline grooves and grooves for the saw tongues in the middle of the span: 


$$
\begin{aligned}
f_{d} & =\frac{5\left(Q_{\text {вал }}-Q_{y o}\right) l^{3}}{384 E\left(J-J_{y o}\right)}=\frac{5(1590-202) 2.37^{3} \times 10^{9}}{384 \times 2.1 \times 10^{5}\left(4.9 \times 10^{5}-2.61 \times 10^{5}\right)} \\
& =\frac{5(1388) \times 10^{9}}{806.4 \times 2.29 \times 10^{10}}=0.376 \mathrm{~mm}
\end{aligned}
$$

Then the relative bending flexibility of the shaft, taking into account the influence of the spline grooves and grooves for the saw tongues, will be equal to:

$$
h_{\text {вu }}=\frac{f_{d}}{l}=\frac{0.376}{2.37}=0.187 \mathrm{~mm} / \mathrm{m}
$$

An important parameter of the saw cylinder itself is the value of the maximum deflection under the action of its own gravity, taking into account the influence of the spline grooves $f_{s g}$ and grooves for the saw tongues in the middle of the span:

$$
\begin{aligned}
f_{s g} & =\frac{5\left(Q_{v a l}-Q_{y o}\right) l^{3}}{384 E\left(J-J_{y o}\right)}=\frac{5(2629-202) 2.37^{3} \times 10^{9}}{384 \times 2.1 \times 10^{5}\left(4.9 \times 10^{5}-2.61 \times 10^{5}\right)} \\
& =\frac{5(2427) \times 10^{9}}{806.4 \times 2.29 \times 10^{10}}=0.618 \mathrm{~mm}
\end{aligned}
$$

Then the relative bending flexibility of the saw cylinder, taking into account the influence of the spline grooves and grooves for the saw tongues, will be equal to:

$$
h_{s g}=\frac{f_{d}}{l}=\frac{0.618}{2.37}=0.261 \mathrm{~mm} / \mathrm{m}
$$

Consider another option, which consists of the formation of a cavity in the shaft body. It should be noted that an attempt was made to use seamless thick-walled hot-rolled pipes for this. Due to the difficulties encountered in the design and design of the technological process for manufacturing the bearing ends of the shaft, this attempt was unsuccessful. The study of the problem shows that it can be solved by drilling a through hole in the shaft, which can be done with a gun drill.

So, in the shaft body (Figure 1 and Figure 2), we will provide for drilling a longitudinal hole with a diameter of $d=40 \mathrm{~mm}$ or a radius of $\mathrm{r}=20 \mathrm{~mm}$.

Determine the decrease in the shaft gravity, which is $1559 \mathrm{~N}$, due to the hole:

$$
Q_{\text {shg }}=\pi r^{2} l \gamma=232 \mathrm{~N}
$$

The decrease in the axial moment of inertia of the shaft cross-section due to the hole will be:

$$
J_{y o}=\frac{\pi d^{4}}{64}=1.256 \times 10^{5} \mathrm{~mm}^{4}
$$

Now let us determine the value of the maximum shaft deflection under the action of its own gravity in the middle of the span, taking into account the influence of the longitudinal through hole: 


$$
\begin{aligned}
f_{\text {sho }} & =\frac{5\left(Q_{\text {shaft }}-Q_{y o}\right) l^{3}}{384 E\left(J-J_{y o}\right)}=\frac{5(1590-232) \times 2.37^{3}}{384 \times 2.1 \times(4.900-0.1256) \times 10^{5}} \\
& =\frac{5 \times 1358 \times 13.31}{806.4 \times 4.77}=0.235 \mathrm{~mm}
\end{aligned}
$$

Then the relative bending flexibility of the shaft, taking into account the influence of the longitudinal through hole:

$$
h_{\text {sho }}=\frac{f_{B o}}{l}=\frac{0.235}{2.37}=0.099 \mathrm{~mm} / \mathrm{m}
$$

Now let us determine the value of the maximum deflection of the saw cylinder under the action of its own gravity in the middle of the span, taking into account the influence of the longitudinal through hole:

$$
\begin{aligned}
f_{f o} & =\frac{5\left(Q_{v a l}-Q_{y o}\right) l^{3}}{384 E\left(J-J_{y o}\right)}=\frac{5(2629-232) \times 2.37^{3} \times 10^{9}}{384 \times 2.1 \times(4.900-0.1256) \times 10^{5}} \\
& =\frac{5 \times 2397 \times 13.31}{806.4 \times 4.77}=0.415 \mathrm{~mm}
\end{aligned}
$$

Then the relative bending compliance of the saw cylinder of the shaft, taking into account the influence of the longitudinal through hole, will be equal to

$$
h_{\text {sho }}=\frac{f_{u o}}{l}=\frac{0.415}{2.37}=0.175 \mathrm{~mm} / \mathrm{m}
$$

Investigation of the issues of improving the design of the saw pack and spacers.

Now let's move on to considering solutions for improving the design of the saw package and spacers.

The design of a saw cylinder with lightweight saws for sawing gins of domestic production has been developed. The saws are made easier by the formation of circular holes on a part of the saw blade surface corresponding to the gap between the slip rings between the groove gaskets (Figure 5).
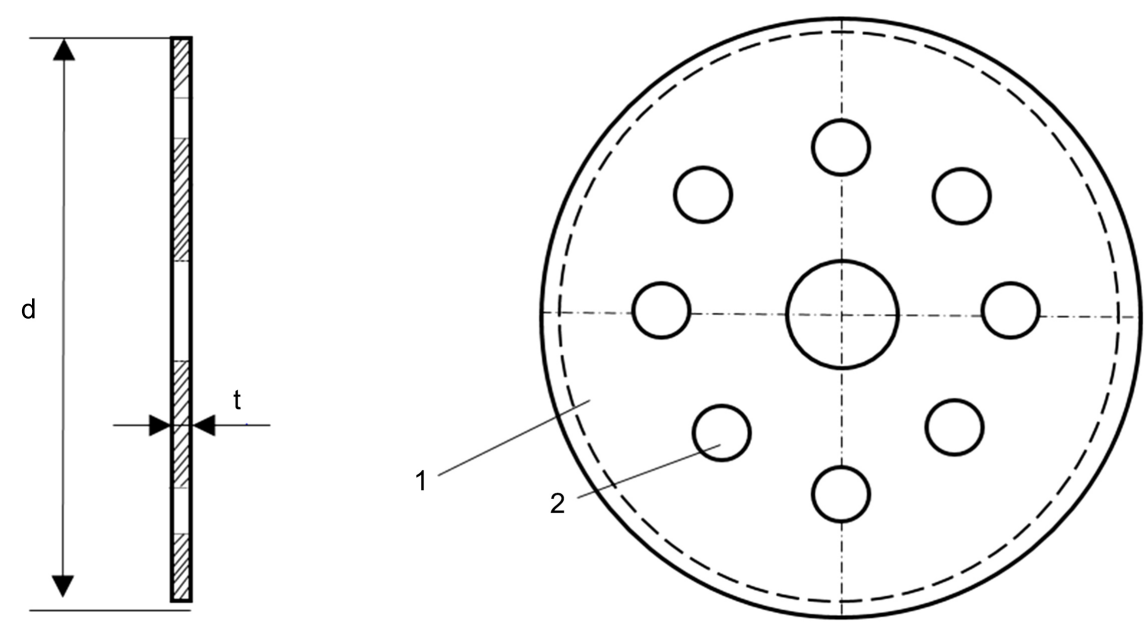

Figure 5. Schematic representation of lightweight saws. $d-i$ is the diameter of the saw blade; $\mathrm{t}$-saw blade thickness; 1 -saw blade; 2 - holes. 
Table 1 shows information for calculating the gravity of the elements of saw cylinders of the existing design of common brands of saw gins of locally production.

Table 2 shows information for calculations to reduce the gravity of the elements of saw cylinders of common brands of saw gins of locally production.

Table 3 shows information on the results of calculations on the reduction of gravity of elements of saw cylinders of common brands of saw gins of locally production.

The information given in Table 1, Table 2 and Table 3 allows the determination of the force of gravity of the improved design of the saw cylinder as follows:

$$
Q_{\text {tot }}=Q_{\text {shaft }}+Q_{\text {saw }}+Q_{\text {prot }}+Q_{\text {guy }}
$$

Table 1. Data of the weights of elements of saw cylinders of the existing design of common brands of saw blades.

\begin{tabular}{|c|c|c|c|c|c|c|c|}
\hline № & Gin brands & Number of saws & $\begin{array}{c}\text { Gravity of one } \\
\text { saw, } \mathrm{N}\end{array}$ & $\begin{array}{l}\text { Gravity of the } \\
\text { saws of one saw } \\
\text { cylinder }(\mathrm{N})\end{array}$ & $\begin{array}{l}\text { Number of saw } \\
\text { cylinder gaskets } \\
\text { (pcs) }\end{array}$ & $\begin{array}{l}\text { Gravity of one } \\
\text { gasket }(\mathrm{N})\end{array}$ & $\begin{array}{l}\text { Saw cylinder } \\
\text { gaskets gravity } \\
\text { (N) }\end{array}$ \\
\hline 1 & $3 \mathrm{XDD}$ & 80 & 5.91 & 472.8 & 79 & 2.4 & 189.6 \\
\hline 2 & $\begin{array}{l}\text { 3XDD (with } \\
\text { UMPD camera) }\end{array}$ & 86 & 5.91 & 508 & 85 & 2.4 & 206.4 \\
\hline 3 & DP-130 & 130 & 5.545 & 720 & 129 & 2.20 & 283.8 \\
\hline
\end{tabular}

Table 2. Data for calculations to reduce the gravity of saw cylinder elements.

\begin{tabular}{|c|c|c|c|c|c|c|c|c|c|c|}
\hline № & Gin brands & $\begin{array}{l}\text { Number } \\
\text { of saws }\end{array}$ & $\begin{array}{c}\text { Hole } \\
\text { diameter } \\
(\mathrm{mm})\end{array}$ & $\begin{array}{c}\text { Number of } \\
\text { holes on one } \\
\text { saw (pcs.) }\end{array}$ & $\begin{array}{c}\text { Surface of } \\
\text { one hole } \\
\left(\mathrm{mm}^{2}\right)\end{array}$ & $\begin{array}{c}\text { Hole } \\
\text { surface per } \\
\text { saw }\left(\mathrm{mm}^{2}\right)\end{array}$ & $\begin{array}{l}\text { Number of } \\
\text { holes on one } \\
\text { saw cylinder } \\
\text { (pcs) }\end{array}$ & $\begin{array}{c}\text { Hole surface } \\
\text { per saw } \\
\text { cylinder } \\
\left(\mathrm{mm}^{2}\right)\end{array}$ & $\begin{array}{c}\text { Gravity } \\
1 \mathrm{~mm}^{2} \\
\text { surface }(\mathrm{H})\end{array}$ & $\begin{array}{c}\text { Gravity of } \\
\text { height of } \\
\text { the holes } \\
\text { (N) }\end{array}$ \\
\hline 1 & 3XDD & 80 & 40 & 8 & 1256 & 10,048 & 640 & 803,840 & 0.00764 & 61.41 \\
\hline 2 & $\begin{array}{c}\text { 3XDD (with } \\
\text { UMPD camera) }\end{array}$ & 86 & 40 & 8 & 1256 & 10,048 & 688 & 864,128 & 0.00764 & 66.02 \\
\hline 3 & DP-130 & 130 & 20 & 16 & 314.2 & 5027 & 2080 & 653,536 & 0.00764 & 49.93 \\
\hline
\end{tabular}

Table 3. The results of calculations to reduce the gravity of the elements of the saw cylinders.

\begin{tabular}{|c|c|c|c|c|c|c|c|c|}
\hline № & Gin brands & $\begin{array}{l}\text { Number } \\
\text { of saws }\end{array}$ & $\begin{array}{c}\text { Gravity } 1 \mathrm{~mm}^{2} \\
\text { surface }(\mathrm{N})\end{array}$ & $\begin{array}{l}\text { Saw blade } \\
\text { gravity }(\mathrm{N})\end{array}$ & $\begin{array}{c}\text { Number of } \\
\text { holes per saw } \\
\text { cylinder }\end{array}$ & $\begin{array}{l}\text { Relief of one } \\
\text { saw cylinder } \\
\text { (N) }\end{array}$ & $\begin{array}{c}\text { Gravity of } \\
\text { lightweight } \\
\text { saw cylinder } \\
\text { saws }(\mathrm{N})\end{array}$ & Difference (\%) \\
\hline 1 & $3 \mathrm{XDD}$ & 80 & 0.00764 & 473 & 640 & 61.41 & 412 & 13 \\
\hline 2 & $\begin{array}{c}\text { 3XDD (with } \\
\text { UMPD camera) }\end{array}$ & 86 & 0.70064 & 508 & 688 & 66.02 & 442 & 13 \\
\hline 3 & DP-130 & 130 & 0.00764 & 720 & 2080 & 49.93 & 670 & 6.95 \\
\hline
\end{tabular}


Here:

$Q_{t o t}$ - the force of gravity of the saw cylinder.

$Q_{\text {saw }}$ - the force of gravity of the saws of the saw cylinder, facilitated by cutting circular holes.

$Q_{\text {prot }}$ - the total gravity of the gaskets.

$Q_{\text {guy }}$ - gravity 2 nuts.

$Q_{\text {shaft }}$ - shaft gravity.

Substitution of values for the saw gin DP-130 gives:

$$
Q_{\text {tot }}=670+283.8+36+1590=2679.8 \mathrm{~N}
$$

As a result of cutting circular holes on the saw blades, the gravity force of the saw cylinder is reduced: on the $3 \mathrm{HDD}$ gin - by $61 \mathrm{~N}$.

$$
\begin{aligned}
& \text { on gin 3XDD (with UMPD camera) - on } 66 \mathrm{~N} \\
& \text { on gin DP-130-50 N }
\end{aligned}
$$

Now let us determine the value of the maximum shaft deflection under the action of its own gravity in the middle of the span, taking into account the effect of cutting circular holes on the saw blades (on the DP-130 gin):

$$
\begin{aligned}
f_{v k} & =\frac{5\left(Q_{\text {shaft }}-Q_{y o}\right) l^{3}}{384 E\left(J-J_{y o}\right)}=\frac{5(1590-50) \times 2.37^{3}}{384 \times 2.1 \times(4.900-0.1256) \times 10^{5}} \\
& =\frac{5 \times 1540 \times 13.31}{806.4 \times 4.77}=0.266 \mathrm{~mm}
\end{aligned}
$$

Then the relative bending flexibility of the shaft, taking into account the effect of cutting circular holes on the saw blades

$$
h_{c o}=\frac{f_{v k}}{l}=\frac{0.266}{2.37}=0.112 \mathrm{~mm} / \mathrm{m}
$$

Now let us determine the value of the maximum deflection of the saw cylinder under the action of its own gravity in the middle of the span, taking into account the effect of cutting circular holes on the saw blades (on the DP-130 gin):

$$
\begin{aligned}
f_{c o} & =\frac{5\left(Q_{t o t}-Q_{y o}\right) l^{3}}{384 E\left(J-J_{y o}\right)}=\frac{5(2629-50) \times 2.37^{3} \times 10^{9}}{384 \times 2.1 \times(4.900-0.1256) \times 10^{5}} \\
& =\frac{5 \times 2579 \times 13.31}{806.4 \times 4.77}=0.446 \mathrm{~mm}
\end{aligned}
$$

Then the relative bending flexibility of the saw cylinder, taking into account the effect of cutting circular holes on the saw blades, will be equal to

$$
h_{c s}=\frac{f_{s c}}{l}=\frac{0.446}{2.37}=0.188 \mathrm{~mm} / \mathrm{m}
$$

Now let us determine the value of the maximum shaft deflection under the action of its own gravity in the middle of the span, taking into account the joint influence of the longitudinal through hole on the shaft and the cutting of circular holes on the saw blades (on the DP-130 gin): 


$$
\begin{aligned}
f_{\text {voc }} & =\frac{5\left(Q_{\text {shaft }}-Q_{y o}\right) l^{3}}{384 E\left(J-J_{y o}\right)}=\frac{5(1590-232-50) \times 2.37^{3}}{384 \times 2.1 \times(4.900-0.1256) \times 10^{5}} \\
& =\frac{5 \times 1308 \times 13.31}{806.4 \times 4.77}=0.226 \mathrm{~mm}
\end{aligned}
$$

Then the relative bending flexibility of the shaft, taking into account the combined effect of the longitudinal through hole on the shaft and the cutting of circular holes on the saw blades.

$$
h_{v o c}=\frac{f_{v o c}}{l}=\frac{0.226}{2.37}=0.095 \mathrm{~mm} / \mathrm{m}
$$

Now let us determine the value of the maximum deflection of the saw cylinder under the action of its own gravity in the middle of the span, taking into account the joint influence of the longitudinal through hole on the shaft and the cutting of circular holes on the saw blades (on the DP-130 gin):

$$
\begin{aligned}
f_{d c h} & =\frac{5\left(Q_{t o t}-Q_{y o}\right) l^{3}}{384 E\left(J-J_{y o}\right)}=\frac{5(2629-232-50) \times 2.37^{3} \times 10^{9}}{384 \times 2.1 \times(4.900-0.1256) \times 10^{5}} \\
& =\frac{5 \times 2347 \times 13.31}{806.4 \times 4.77}=0.406 \mathrm{~mm}
\end{aligned}
$$

Then the relative bending compliance of the saw cylinder will be equal to

$$
h_{d c h}=\frac{f_{d c h}}{l}=\frac{0.406}{2.37}=0.171 \mathrm{~mm} / \mathrm{m}
$$

\section{Conclusion}

The study shows that the improvement in the design of the saw cylinder of the gin by lightening the saw cylinder shaft by drilling a longitudinal through hole and cutting circular holes on the saw blades is accompanied by a relatively large decrease in mass and a relatively smaller decrease in the axial moment of inertia of the cross-sectional area of the shaft, which ensures a decrease in the maximum deflection the saw cylinder of the gin DP-130 under the action of its own gravity in the middle of the span from $0.450 \mathrm{~mm}$ to $0.406 \mathrm{~mm}$, or by $10.8 \%$, which should be considered a good result.

\section{Conflicts of Interest}

The authors declare no conflicts of interest regarding the publication of this paper.

\section{References}

[1] Jabborov, G., et al. (1987) Technology of Primary Processing of Seed Cotton. 328 p.

[2] Yunusov, S., Djuraev, A. and Mirzaumidov, A. (2018) Analysis of slitovnogo pilnogo vala na prochnost v staticheskom sostoyanii. Journal of Fergana Polytechnic Institute, 2, 40-45.

[3] Djuraev, A. and Khudoikulov, Sh. (2019) Analysis of the Results of Structural Development Tests with a Support That Reduces the Bending of the Cylindrical Shaft Bearings. NamMTI Scientific and Technical Journal, No. 2, 119-123. 